\title{
Ultrasonographic Measurement of Thickness of the Thyrohyoid Muscle: A Pilot Study
}

\author{
Ji Hwan Cheon, MD, Du Hyeon Nam, MD, Howard Kim, MD, Dong Youl Lee, MD, \\ Youn Kyung Cho, MD, Eun Young Kang, MD, Sung Hoon Lee, MD \\ Department of Physical Medicine and Rehabilitation, Kwangju Christian Hospital, Gwangju, Korea
}

\begin{abstract}
Objective To evaluate the normal thickness of the thyrohyoid muscle, which is one of the key muscles related to swallowing, by ultrasonography.

Methods The thickness of the left and right thyrohyoid muscles was measured in normal male and female adults ranging in age from 20 to 79 years by ultrasonography. The groups were classified according to age as follows: subjects ranging in age from 20 to 39 years were classified into group A, subjects ranging in age from 40 to 59 years were classified into group B, and subjects ranging in age from 60 to 79 years were classified into group C. The measurement level was the line that joins the upper tip of the superior thyroid notch and the oblique line of the thyroid cartilage. Also, a correlation with the thyrohyoid muscle was investigated by collecting information regarding height, weight, body mass index (BMI), age, and gender of subjects in the healthy group.

Results The number of subjects in each group was as follows: group A ( $n=82)$, group B ( $n=62)$, and group C $(n=60)$. Also, the thicknesses of the left and right muscles were $2.72 \pm 0.65 \mathrm{~mm}$ and $2.87 \pm 0.76 \mathrm{~mm}$ in group A, $2.83 \pm 0.61 \mathrm{~mm}$ and $2.93 \pm 0.67 \mathrm{~mm}$ in group $\mathrm{B}$, and $2.59 \pm 054 \mathrm{~mm}$ and $2.73 \pm 0.55 \mathrm{~mm}$ in group $\mathrm{C}$, respectively. Thyrohyoid muscle had a correlation with height, weight, and BMI. The thickness of the left and right thyrohyoid muscles was greater in male subjects than in female subjects and the right side muscle was thicker than the left side muscle.

Conclusion The average thickness of the left and right thyrohyoid muscles was $3.20 \pm 0.54 \mathrm{~mm}$ in male subjects and $2.34 \pm 0.37 \mathrm{~mm}$ in female subjects. The thickness of the thyrohyoid muscle was positively correlated with height, weight, and BMI, and the thyrohyoid muscle was thicker in male subjects than in female subjects and the right side muscle was thicker than the left side muscle.
\end{abstract}

Keywords Deglutition disorders, Neck muscles, Ultrasonography

\section{INTRODUCTION}

Oropharyngeal swallowing is a consecutive, complex sensorimotor phenomenon which involves several muscles. It occurs due to regulation of the central nervous system and the peripheral nervous system [1]. Dysphagia

Received December 16, 2015; Accepted February 22, 2016

Corresponding author: SungHoon Lee

Department of Physical Medicine and Rehabilitation, Kwangju Christian Hospital, 37 Yangnim-ro, Nam-gu, Gwangju 61661, Korea. Tel: +82-62-6505162, Fax: +82-62-671-7447, E-mail: starhoon3@hanmail.net

ORCID: Ji Hwan Cheon (http://orcid.org/0000-0001-5921-3084); Du Hyeon Nam (http://orcid.org/0000-0001-7360-8699); Howard Kim (http://orcid. org/0000-0002-1123-9485); Dong Youl Lee (http://orcid.org/0000-0002-5740-1468); Youn Kyung Cho (http://orcid.org/0000-0003-4906-6089); Eun Young Kang (http://orcid.org/0000-0001-6805-5727); Sung Hoon Lee (http://orcid.org/0000-0002-2071-7936).

(c) This is an open-access article distributed under the terms of the Creative Commons Attribution Non-Commercial License (http://creativecommons.org/ licenses/by-nc/4.0) which permits unrestricted noncommercial use, distribution, and reproduction in any medium, provided the original work is properly cited. Copyright ( 2016 by Korean Academy of Rehabilitation Medicine 
means swallowing disability. It can result from several diseases, such as stroke, Parkinson disease and multiple sclerosis, and its prevalence rate reaches $22 \%$ in the population aged over 55 years [2]. Several muscles participate in the swallowing process, and these muscles are classified as suprahyoid muscles (anterior belly of the digastric, posterior belly of the digastric, geniohyoid, and mylohyoid muscles) and infrahyoid muscles (thyrohyoid, sternohyoid, sternothyroid, and omohyoid muscles). Recently, some researches have been conducted to identify the muscles which should be targeted by electrical stimulation and dysphagia exercise to improve the swallowing function effectively $[3,4]$. The thyrohyoid muscle is one of the muscles under the spotlight with respect to hyolaryngeal elevation [5]. The thyrohyoid muscle is a key muscle in the infrahyoid muscle group, which transfers the power from the suprahyoid muscle group to the cricothyroid complex so that the upper esophageal sphincter can open [6]. The thyrohyoid muscle is a quadrilateral shaped skeletal muscle which originates from the oblique line of the thyroid cartilage and is inserted into the greater cornu of the hyoid bone. Its main action is to depress the hyoid bone and elevate the larynx while receiving innervation via the first cervical nerve followed by the hypoglossal nerve [7]. In dysphagic patients, there is no ultrasonography study to assess the thickness of the thyrohyoid muscle, and also there is no study comparing the difference in thickness of the thyrohyoid muscle between normal people and dysphagic patients. To determine the difference between the two groups, the data on the thyrohyoid muscle in normal people without any swallowing disorder are needed. Thus, this pilot study aimed to evaluate the thickness of the thyrohyoid muscle in normal people, which can be utilized as a comparative study in dysphagic patients, and the results of the study can be used to assess the effect of dysphagia rehabilitation.

\section{MATERIALS AND METHODS}

This study was approved by the Institutional Review Board of Kwangju Christian Hospital, and it was performed in healthy adults from November 5, 2015 to January 23,2016 . The definition of a healthy adult was a person who is not taking any medication currently, and who does not have any previous history of neck surgery, diabetes mellitus, thyroid disease, myopathy, tuberculosis or any similar disease. A total of 204 subjects were enrolled in this study.

The healthy group was divided into groups A, B, and C according to the age as 20 to 39 years old, 40 to 59 years old, and 60 to 79 years old, respectively. The thyrohyoid muscle has a specific property that its thickness changes according to the posture in which the measurement is performed. Its thickness is increased when the neck is flexed because of the increase in muscle belly, and its thickness is decreased when the neck is extended because of the decrease in muscle belly. Therefore, the neck position was maintained consistently when the thickness of the thyrohyoid muscle was measured. In the supine position, a vertical line which connects the lower margin of the mandibular body tip and the hyoid bone was perpendicular to the horizontal line which connects the upper margin of the thyroid cartilage and the hyoid bone (Fig. 1).
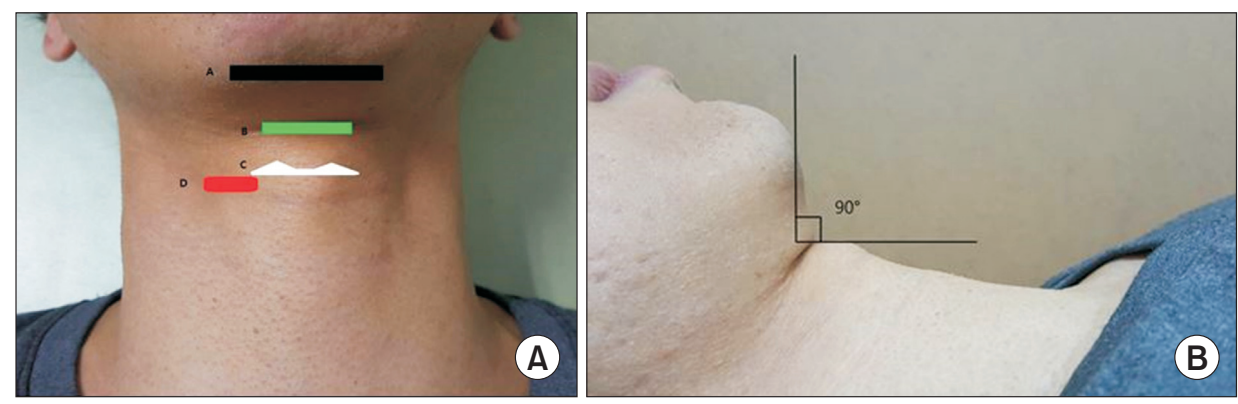

Fig. 1. (A) Measurement of the thyrohyoid muscle thickness (A, tip of the mandibular body; B, hyoid bone; C, upper margin of the thyroid cartilage; D, confirms location during measurement of the thyrohyoid muscle). (B) Head and neck position during measurement of the thyrohyoid muscle. Vertical line which connects the lower margin of the mandibular body tip and the hyoid bone must be perpendicular to the horizontal line which connects the upper margin of the thyroid cartilage and the hyoid bone. 
The physician was a medical specialist in rehabilitation medicine whose ultrasonography experience was more than 5 years and the experimenter measured the thickness of the thyrohyoid muscle consistently. Ultrasonography (LOGIQ E9; GE Healthcare, Little Chalfont, UK) was used as the measurement technique. The article by Gervasio et al. [8] was referred for identifying the thyrohyoid muscle by ultrasonography. Initially, the superior thyroid notch was identified and a line was drawn which connects the upper margin of the oblique line of the thyroid cartilage. By placing the probe on this line, the thyrohyoid muscle, which is located under the sternohyoid muscle, was identified, and the bulkiest point was measured in the axial direction. With respect to measuring the thickness, it was calculated by a built-in function of length measurement in ultrasonography equipment (Figs. 2, 3).

The thickness values were averaged after measuring the thicknesses of the left and right thyrohyoid muscles three times each. Simultaneously, the height and weight in the healthy group were measured to calculate body mass index (BMI) in an examination room. Also, information on age and sex was collected. SPSS ver. 21.0 (IBM, Armonk, NY, USA) was used for statistical analysis, and independent t-test, one sample t-test and ANOVA test were applied. Bonferroni correction was used as the posthoc analysis. Pearson correlation coefficient analysis was used as the correlation coefficient analysis. Linear regression analysis was used for estimating the thickness of the thyrohyoid muscle depending on the weight, in male and female subjects.

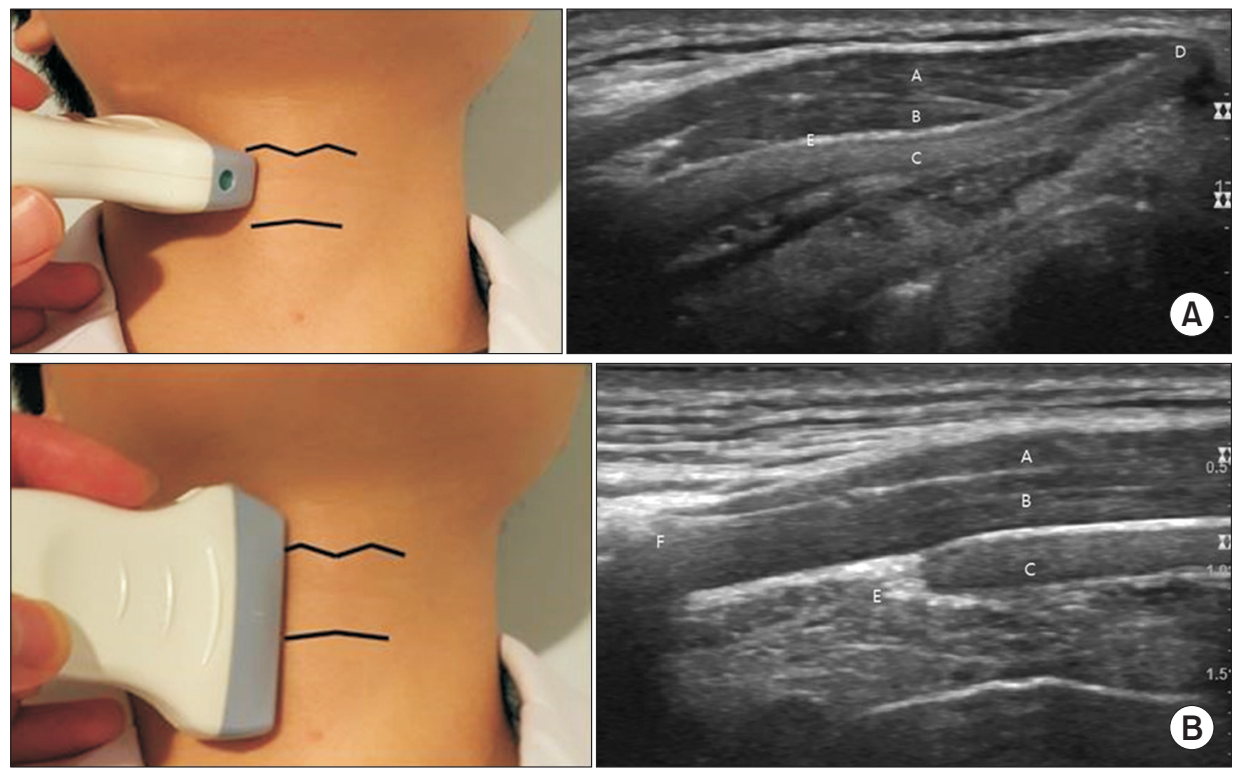

Fig. 2. Axial (A) and longitudinal (B) probe locations and correlated ultrasonographic findings of the right thyrohyoid muscle in a normal subject (a 42-year-old healthy male). The subject weighed 60 $\mathrm{kg}$ and thyrohyoid muscle thickness was $2.8 \mathrm{~mm}$. A, sternohyoid muscle; $\mathrm{B}$, thyrohyoid muscle; $\mathrm{C}$, thyroid cartilage; $\mathrm{D}$, superior thyroid notch; E, upper margin of the thyroid cartilage; F, hyoid bone.
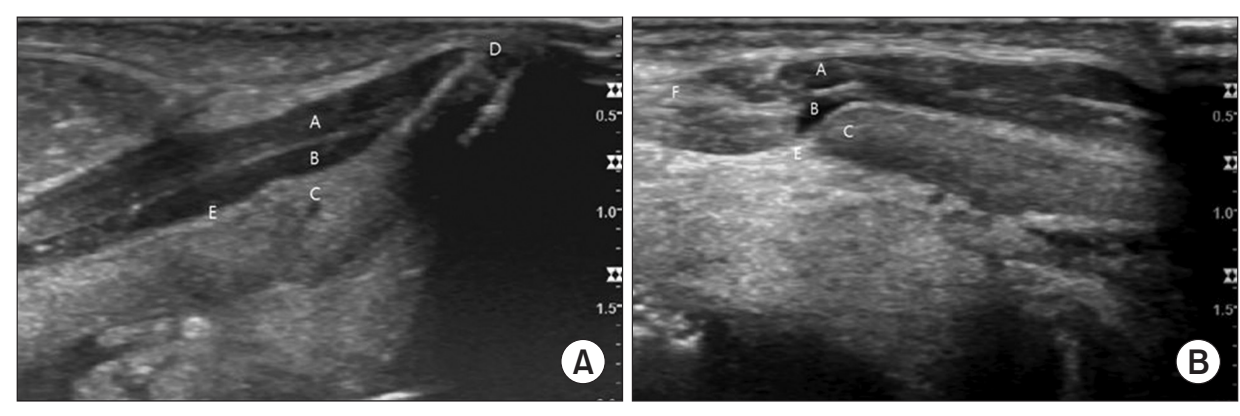

Fig. 3. Axial (A) and longitudinal (B) ultrasonographic findings of the right thyrohyoid muscle in a 45-year-old male patient with dysphagia after 3 months from the left middle cerebral artery infarction. The patient weighed $59 \mathrm{~kg}$ and muscle thickness was $1.7 \mathrm{~mm}$. Thickness was decreased compared with that in a healthy male. A, sternohyoid muscle; B, thyrohyoid muscle; C, thyroid cartilage; D, superior thyroid notch; E, upper margin of the thyroid cartilage; F, hyoid bone. 
Table 1. Characteristics and the thickness of the left/right thyrohyoid muscles

\begin{tabular}{lcccc}
\hline & Group A (n=82) & Group B (n=62) & Group C (n=60) & p-value \\
\hline Sex (male:female) & $44: 38$ & $30: 32$ & $30: 30$ & \\
\hline Height $(\mathrm{cm})$ & $168.9 \pm 9.0$ & $165.2 \pm 8.2$ & $161.7 \pm 8.0$ & $<0.001^{* *}$ \\
Weight $(\mathrm{kg})$ & $63.6 \pm 14.3$ & $63.9 \pm 11.2$ & $61.4 \pm 7.74$ & 0.421 \\
BMI $\left(\mathrm{kg} / \mathrm{m}^{2}\right)$ & $22.1 \pm 3.5$ & $23.2 \pm 2.6$ & $23.1 \pm 3.5$ & 0.067 \\
Muscle depth (mm) & & & & \\
Left & $2.72 \pm 0.65$ & $2.83 \pm 0.61$ & $2.59 \pm 0.54$ & 0.108 \\
\hline Right & $2.87 \pm 0.76$ & $2.93 \pm 0.67$ & $2.73 \pm 0.55$ & 0.234 \\
\hline
\end{tabular}

Values are presented as mean \pm standard deviation.

BMI, body mass index.

${ }^{* *} \mathrm{p}<0.005$.

Table 2. Thickness of the left/right thyrohyoid muscles in male and female subjects

\begin{tabular}{|cccc}
\hline $\begin{array}{c}\text { Muscle depth of } \\
\text { thyrohyoid }\end{array}$ & $\begin{array}{c}\text { Male } \\
(\mathbf{n}=\mathbf{1 0 4})\end{array}$ & $\begin{array}{c}\text { Female } \\
(\mathbf{n}=\mathbf{1 0 0})\end{array}$ & p-value \\
\hline Left side (mm) & & & \\
\hline Group A & $3.09 \pm 0.59$ & $2.29 \pm 0.43$ & $<0.001^{* *}$ \\
\hline Group B & $3.35 \pm 0.38$ & $2.33 \pm 0.31$ & $<0.001^{* *}$ \\
\hline Group C & $2.89 \pm 0.49$ & $2.29 \pm 0.41$ & $<0.001^{* *}$ \\
\hline Total & $3.11 \pm 0.53$ & $2.31 \pm 0.39$ & $<0.001^{* *}$ \\
\hline Right side (mm) & & & \\
\hline Group A & $3.33 \pm 0.70$ & $2.34 \pm 0.39$ & $<0.001^{* *}$ \\
\hline Group B & $3.46 \pm 0.49$ & $2.43 \pm 0.36$ & $<0.001^{* *}$ \\
\hline Group C & $3.07 \pm 0.45$ & $2.38 \pm 0.40$ & $<0.001^{* *}$ \\
\hline Total & $3.29 \pm 0.59$ & $2.38 \pm 0.38$ & $<0.001^{* *}$ \\
\hline
\end{tabular}

Values are presented as mean or mean \pm standard deviation.

${ }^{* *} \mathrm{p}<0.005$.

\section{RESULTS}

The number of subjects and the gender of subjects in the subgroups were as follows: group $A(n=82$; male 44 , female 38$)$, group $B(n=62$; male 30 , female 32$)$, and group C ( $\mathrm{n}=60$; male 30 , Female 30$)$.

There was a statistically significant difference among subgroups in terms of height $(\mathrm{p}<0.001)$. The height of subjects in group A was statistically significantly greater than that of subjects in group $\mathrm{C}(\mathrm{p}<0.001)$.

There was no statistically significant difference among groups in terms of weight and BMI.

The thicknesses of the left and right thyrohyoid muscles in each group were as follows: group A, $2.72 \pm 0.65 \mathrm{~mm}$ and $2.87 \pm 0.76 \mathrm{~mm}$; group $\mathrm{B}, 2.83 \pm 0.61 \mathrm{~mm}$ and $2.93 \pm 0.67$
Table 3. Thickness of the left/right thyrohyoid muscles

\begin{tabular}{lccc}
\hline & Left side & Right side & p-value \\
\hline Group A $(\mathrm{n}=82)$ & $2.72 \pm 0.65$ & $2.87 \pm 0.76$ & $<0.001^{* *}$ \\
Group B $(\mathrm{n}=62)$ & $2.83 \pm 0.61$ & $2.93 \pm 0.67$ & $<0.001^{* *}$ \\
Group C $(\mathrm{n}=60)$ & $2.59 \pm 0.54$ & $2.73 \pm 0.55$ & $<0.001^{* *}$ \\
Total $(\mathrm{n}=204)$ & $2.71 \pm 0.61$ & $2.85 \pm 0.68$ & $<0.001^{* *}$ \\
\hline
\end{tabular}

Values are presented as mean or mean \pm standard deviation.

${ }^{* *} \mathrm{p}<0.005$.

$\mathrm{mm}$; group C, $2.59 \pm 0.54 \mathrm{~mm}$ and $2.73 \pm 0.55 \mathrm{~mm}$ (Table 1 ). There was no statistically significant difference in the thickness of the thyrohyoid muscle among groups.

The thicknesses of left and right side muscles in groups were statistically significantly greater in male subjects than in female subjects of groups A, B, and C-left side muscle (group $\mathrm{A}, \mathrm{p}<0.001$; group $\mathrm{B}, \mathrm{p}<0.001$; group $\mathrm{C}$, $\mathrm{p}<0.001$ ) and right side muscle (group $\mathrm{A}, \mathrm{p}<0.001$; group $\mathrm{B}, \mathrm{p}<0.001$; group $\mathrm{C}, \mathrm{p}<0.001$ ) (Table 2).

Also, the thickness of the right side muscle was statistically significantly greater than that of the left side muscle (group $\mathrm{A}, \mathrm{p}<0.001$; group $\mathrm{B}, \mathrm{p}<0.001$; group $\mathrm{C}, \mathrm{p}<0.001$ ) (Table 3).

In all groups, the thickness of the thyrohyoid muscle was positively correlated with height (correlation coefficient $=0.67, \mathrm{p}<0.001$ ), weight (correlation coefficient $=0.80$, $\mathrm{p}<0.001$ ), and BMI (correlation coefficient $=0.52$, $\mathrm{p}<0.001$ ), and the correlation coefficient of weight was the highest. There was no significant correlation with age $(p=0.41)$ (Fig. 4).

Using linear regression analysis, the graph which estimated the average thickness of the left and right thyrohyoid muscles based on the weight of male and female 
(A)

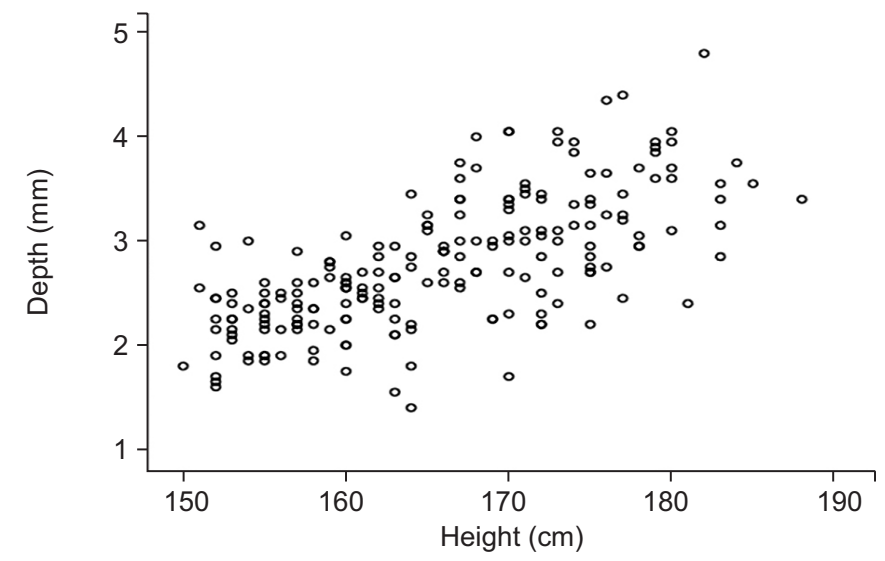

(B)

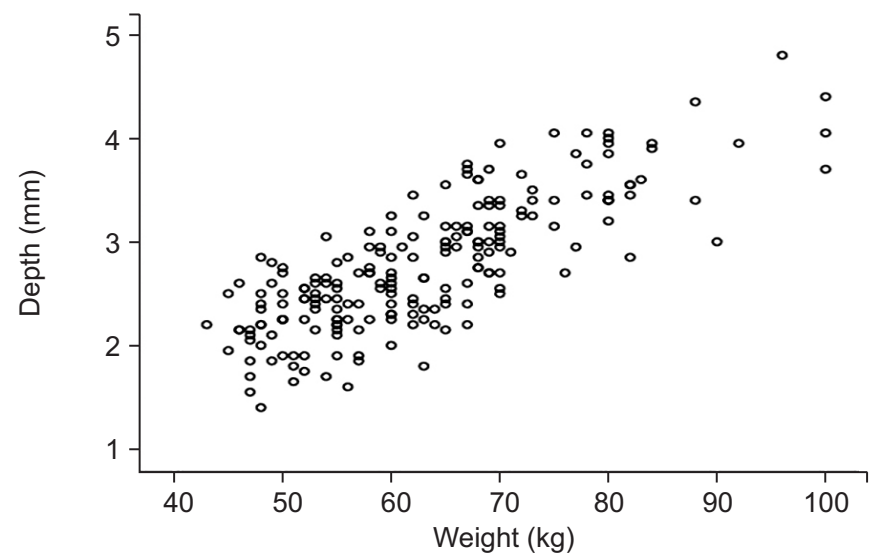

Fig. 4. Correlations (A) between height and thyrohyoid muscle depth, (B) between weight and thyrohyoid muscle depth.
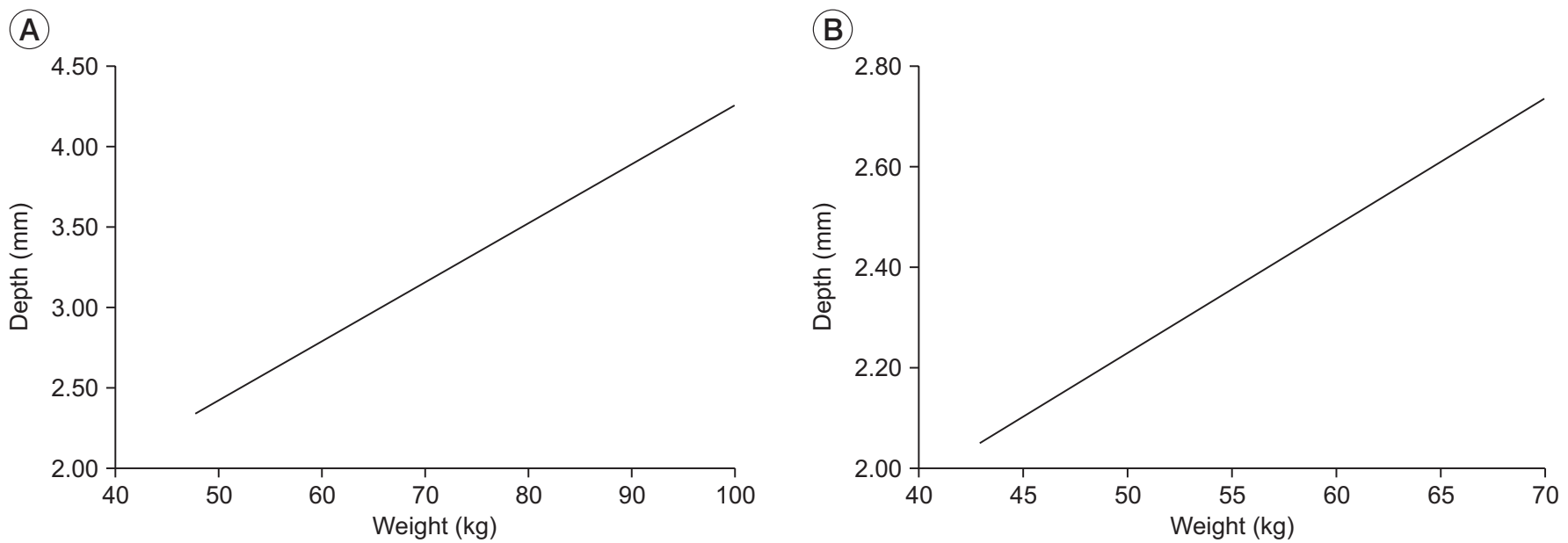

Fig. 5. (A) Expected average thickness ( $\mathrm{mm}$ ) of the left and right thyrohyoid muscles based on weight (kg) of male subjects using linear regression analysis. The muscle thickness was increased in proportion to the weight increase. (B) Expected average thickness $(\mathrm{mm})$ of the left and right thyrohyoid muscles based on weight $(\mathrm{kg})$ of female subjects using linear regression analysis. The muscle thickness increased in proportion to the weight increase.

subjects is presented in Fig. 5. The muscle thickness was increased in proportion to the weight increase.

\section{DISCUSSION}

In recent studies, a decrease in the reciprocating motion of the hyoid bone and a decrease in epiglottic rotation were considered as the causes of swallowing function in dysphagic patients, especially stroke patients [9]. Therefore, studies assessing the muscles related to the reciprocating motion of the hyoid bone and epiglottis were performed. In some of the articles, cadaveric or functional MRI was used [10,11]. But, the articles which are related to ultrasonography are very rare. During normal swallowing, the important function in the pharyngeal stage is successful airway protection during passage of food. This function is possible because of the upward and forward contraction of the hyolaryngeal complex. At this time, the most important muscles are suprahyoid muscles which raise the hyoid bone, and the thyrohyoid muscle which causes laryngeal elevation [12].

Considering the procedure for transmission of power, the thyrohyoid muscle has the largest relative contribution in laryngeal elevation and upper esophageal sphinc- 
ter opening [6].

The study which showed that the degree of contraction of the thyrohyoid muscle was increased during swallowing after the shaker exercise compared to that before the exercise also proves the importance of the thyrohyoid muscle [13].

Therefore, this study focused on the ultrasonographic characteristics of the thyrohyoid muscle in the healthy group. The thyrohyoid muscle was easily measured by ultrasonography compared with the suprahyoid muscle group and it had high consistency. The length and width parameters of the thyrohyoid muscle, which were measured by using ultrasonography in a prestudy, were excluded from measurement due to the issue of consistency. Moreover, the origin and insertion sites of the thyrohyoid muscle were defined according to the shape of the thyroid cartilage and the hyoid bone in each subject. Thus, we concluded that the length and width were not appropriate for the parameters related to muscle activity. A previous study showed that the muscle power was directly correlated with the cross-sectional area of the muscle and the parallel muscle power was proportional to the bulkiest point of the cross-sectional area [14]. Therefore, the cross-sectional thickness at the bulkiest point of the thyrohyoid muscle was supposed to be measured in this study. Also, to improve the statistical quality, the number of subjects in the experimental group was considered to ensure adequate data for a parametric test.

Weight had the highest correlation with the thyrohyoid muscle. As a result, the thickness of the thyrohyoid muscle was greatest in group B (40 to 59 years old). This result was consistent with epidemiologic statistics which shows that the 30 to 49 years old population has the highest proportion of obese people [15]. Since the weight was proportional to the intake and activity level of the muscle related to swallowing, it was supposed that the muscle became hypertrophied.

Although this study was performed by hypothesizing that muscle thickness was highly correlated with age, the result was not the same as our hypothesis because the most important factor for muscle thickness was weight. In addition, it can be inferred that there was no statistically significant difference in muscle thickness according to age because there was no statistically significant difference in weight according to the age group. Thus, it can be considered that the thickness of the thyrohyoid muscle is a useful parameter related to swallowing since it was not highly affected by age.

The thickness of the thyrohyoid muscle in male subjects was greater than that in female subjects, like most skeletal muscles. This may be due to the difference in weight between male and female subjects in the healthy group (average weight of male subjects, $71.19 \pm 10.05 \mathrm{~kg}$; average weight of female subjects, $54.54 \pm 6.08 \mathrm{~kg})(\mathrm{p}<0.001)$.

Moreover, the fact that male subjects have more androgen hormones involved in the generation of muscle can also be one of the reasons.

Unexpectedly, there was a difference between the left and right side thickness of the thyrohyoid muscle, and the right side muscle thickness was statistically and significantly greater. The mastication habit may be considered as one of the reasons. A previous study supposed that there was a chewing side preference in each person [16]. In our study, the fact that right side prevalence is higher than left side prevalence is supposed to be the reason. Later, a quantified study on both the habitual side of mastication and the difference between the right and left side thickness of the thyrohyoid muscle is required.

Subjects who were below 20 years of age and above 80 years of age were excluded, which is a limitation of this study. Thus, further study should be performed among various age groups.

In conclusion, the average thickness of the left and right thyrohyoid muscles in male and female subjects was $3.20 \pm 0.54 \mathrm{~mm}$ and $2.34 \pm 0.37 \mathrm{~mm}$, respectively. This thickness was positively correlated with height, weight, and BMI. Furthermore, the average thickness was significantly greater in male subjects than in female subjects, and the right side muscle was significantly thicker than the left side muscle.

Later, this pilot study can become the foundation of the study assessing the thickness of the thyrohyoid muscle in patients with a swallowing disorder.

\section{CONFLICT OF INTEREST}

No potential conflict of interest relevant to this article was reported.

\section{REFERENCES}

1. Humbert IA, German RZ. New directions for under- 
standing neural control in swallowing: the potential and promise of motor learning. Dysphagia 2013;28:110.

2. Howden CW. Management of acid-related disorders in patients with dysphagia. Am J Med 2004;117 Suppl 5A:44S-48S.

3. Beom J, Kim SJ, Han TR. Electrical stimulation of the suprahyoid muscles in brain-injured patients with dysphagia: a pilot study. Ann Rehabil Med 2011;35:322-7.

4. Kim SH, Oh BM, Han TR, Jeong HJ, Sim YJ. Different movement of hyolaryngeal structures by various application of electrical stimulation in normal individuals. Ann Rehabil Med 2015;39:535-44.

5. Leelamanit V, Limsakul C, Geater A. Synchronized electrical stimulation in treating pharyngeal dysphagia. Laryngoscope 2002;112:2204-10.

6. Matsuo K, Palmer JB. Anatomy and physiology of feeding and swallowing: normal and abnormal. Phys Med Rehabil Clin N Am 2008;19:691-707.

7. Moore KL, Dalley AF. Clinically oriented anatomy. 4th ed. Philadelphia: Lippincott Williams \& Wilkins; 1999. p. 1012-7.

8. Gervasio A, Mujahed I, Biasio A, Alessi S. Ultrasound anatomy of the neck: the infrahyoid region. J Ultrasound 2010;13:85-9.

9. Han TR, Bang MS, Paik NJ, Jeon JY, Kim SJ, Lee HJ. Digital image motion analysis of the pharyngeal movement during swallowing in dysphagia patients. J Korean Acad Rehabil Med 2002;26:693-8.
10. Pearson WG Jr, Langmore SE, Yu LB, Zumwalt AC. Structural analysis of muscles elevating the hyolaryngeal complex. Dysphagia 2012;27:445-51.

11. Pearson WG Jr, Hindson DF, Langmore SE, Zumwalt AC. Evaluating swallowing muscles essential for hyolaryngeal elevation by using muscle functional magnetic resonance imaging. Int J Radiat Oncol Biol Phys 2013;85:735-40.

12. Cifu DX, Kaelin DL, Kowalske KJ, Lew HL, Miller MA, Ragnarsson KT, et al. Braddom's physical medicine \& rehabilitation. 5th ed. Philadelphia: Elsevier; 2016. p. 59.

13. Mepani R, Antonik S, Massey B, Kern M, Logemann J, Pauloski B, et al. Augmentation of deglutitive thyrohyoid muscle shortening by the Shaker exercise. Dysphagia 2009;24:26-31.

14. Maughan RJ, Watson JS, Weir J. Strength and crosssectional area of human skeletal muscle. J Physiol 1983;338:37-49.

15. Kang HT, Shim JY, Lee HR, Park BJ, Linton JA, Lee YJ. Trends in prevalence of overweight and obesity in Korean adults, 1998-2009: the Korean National Health and Nutrition Examination Survey. J Epidemiol 2014; 24:109-16.

16. Ishii H. A study on the relationships between imbalance of stomatognathic function and asymmetry of craniofacial morphology, and the center of gravity of the upright posture. Osaka Daigaku Shigaku Zasshi 1990;35:517-56. 